\title{
Breast cancer: role of polymorphisms in biotransformation enzymes
}

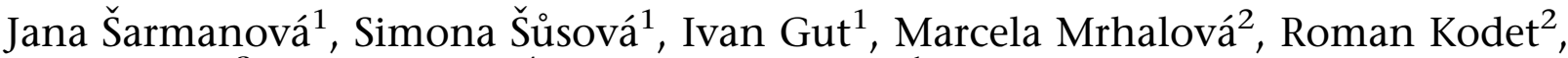 \\ Jan Adámek ${ }^{3}$, Zdeněk Roth ${ }^{4}$ and Pavel Souček*,1
}

${ }^{1}$ Group for Biotransformations, Center of Occupational Diseases, National Institute of Public Health, Prague 10, Czech Republic; ${ }^{2}$ Department of Pathology, Teaching Hospital Motol, V úvalu 84, Prague 5, Czech Republic; ${ }^{3}$ Department of Surgery, Teaching Hospital Motol, V úvalu 84, Prague 5, Czech Republic; ${ }^{4}$ Department of Statistics, National Institute of Public Health, Prague 10, Czech Republic

We aimed at determining whether any association exists between genetic polymorphisms in epoxide hydrolase (EPHX1), NADPH-quinone oxidoreductase (NQO1), glutathione S-transferases (GSTM1/P1/T1) and individual susceptibility to breast cancer. Polymerase chain reaction-restriction fragment length polymorphism-based genotyping assays were used to determine the frequency of polymorphisms in EPHX1 (exons 3 and 4), NQO1 (exon 6), GSTM1 (deletion), GSTP1 (exon 5), and GSTT1 (deletion) in a case-control study comprised of 238 patients with breast cancer and 313 healthy individuals. The distribution of genotypes in exon 6 of NQO1 was significantly different between the control group and breast cancer cases. Age-adjusted odds ratio (OR) for variant genotype $N Q 01{ }^{*} 2 /{ }^{*} 2$ was 3.68 (confidence interval $(C I)=1.41-9.62, P=0.008)$. Association of GSTP1 $2 /{ }^{*} 2$ genotype as well as that of low EPHX1 activity deduced by combinations of genotypes in exons 3 and 4 with breast cancer was suggestive, but nonsignificant. Individuals simultaneously lacking GSTM1 and carrying at least one GSTP1 variant allele were at significantly higher risk of breast cancer $(\mathrm{OR}=2.03, \mathrm{Cl}=1.18-3.50, P=0.010)$. Combinations of either GSTM1null or GSTP1*2 with low activity of EPHX1 presented significant risk of breast cancer $(\mathrm{OR}=1.88, \mathrm{Cl}=1.00-3.52, P=0.049$ and $\mathrm{OR}=2.40, \mathrm{Cl}=1.15-5.00, P=0.019$, respectively $)$ as well. In conclusion, the results suggest that genetic polymorphisms in biotransformation enzymes may play a significant role in the development of breast cancer. European Journal of Human Genetics (2004) 12, 848-854. doi:10.1038/sj.ejhg.5201249

Published online 28 July 2004

Keywords: EPHX1; NQO1; GST; polymorphisms; breast; cancer

\section{Introduction}

Breast cancer is the most common malignancy and cause of death in the Western world. If current breast cancer rates remain constant, a woman born today has a one in 10 chance of developing breast cancer. ${ }^{1}$ High-penetrance

*Correspondence: Dr P Souček, Group for Biotransformations, Center of Occupational Diseases, National Institute of Public Health, Šrobárova 48, Prague 10, 10042, Czech Republic. Tel: +420 267082711; Fax: +420 267311236; E-mail: psoucek@szu.cz

Received 3 February 2004; revised 13 May 2004; accepted 25 May 2004 genes account for only 5\% of cases, whereas polymorphic low-penetrance genes acting in concert with lifestyle/ environmental risk factors are likely to account for a much higher proportion.

Our study aimed at determining whether any association exists between genetic polymorphisms in EPHX1, NQO1, GSTM1, GSTP1, GSTT1 and individual susceptibility to breast cancer. For this study, we have chosen enzymes with relevance to metabolism of environmental contaminants and polymorphisms with known effect on protein expression, activity, and affinity. 
The genetically variable biotransformation enzymes: epoxide hydrolase (EPHX1, EC 3.3.2.3), NAD(P)H:quinone oxidoreductase (NQO1, EC 1.6.99.2), and glutathione $S$-transferases (GST, EC 2.5.1.18) metabolize and conjugate drugs, carcinogens, and natural products. ${ }^{2}$ In addition, high number of human cancer cases result from exposure to environmental carcinogens, ${ }^{3}$ suggesting that individual effectiveness in the detoxification of these chemicals may influence susceptibility to malignant disease.

EPHX1 catalyzes the hydrolysis of epoxides to lessreactive trans-dihydrodiols. ${ }^{4}$ The absence of genetic complexity of EPHX1, located on chromosome 1 (1q42.1), is in striking contrast with other biotransformation enzymes. Two common alleles of EPHX1 can be detected by their mutations in exon 3 (site T337C, amino-acid change Tyr113His, allele nomenclature $\left.E P H X 1{ }^{*} 1{ }^{*} 3\right)$ and exon 4 (A415G, His139Arg, EPHX1*1/*4), which confer slow and fast enzyme activity, respectively. ${ }^{5}$ The $E P H X 1 * 3 /{ }^{*} 3$ genotype was associated with a decreased risk of invasive ovarian cancer of the endometrioid subtype. ${ }^{6}$

NQO1 gene located on chromosome 16 (16q22.1) encodes an obligate two-electron reductase that can either bioactivate or detoxify quinones and has been proposed to play an important role in chemoprevention. ${ }^{7}$ The polymorphism in exon 6 of NQO1 (C609T, Pro187Ser, NQO1 ${ }^{*} 1$ / $\left.{ }^{*} 2\right)$ was associated with the risk of colorectal cancer ${ }^{8}$ and myeloid leukemia. ${ }^{9}$ The case-control study of Hamajima et $a l^{10}$ on Japanese suggested that the variant $N Q O 1{ }^{*} 2{ }^{*} 2$ genotype increased the risk of cancers of the esophagus and lung but not breast. Siegelmann-Danieli and Buetow ${ }^{11}$ published that NQO1 polymorphism might affect the histology development of breast tumors.

GSTs are responsible for the detoxification of many carcinogens. GSTM1 is located on chromosome 1 (1p13.3), and meta-analysis of epidemiological studies showed that GSTM1 deficiency caused by homozygous deletion of the gene (null or GSTM ${ }^{*} 2 /{ }^{*} 2$ genotype) confers an increased risk of lung cancer. ${ }^{12}$ Another gene deletion at the GSTT1 locus (22q11.2, null or GSTT1*2/*2 genotype) was reported by Pemble et al. ${ }^{13}$ The GSTM1null genotype was significantly associated with breast cancer risk in postmenopausal women ${ }^{14}$ but quite opposite finding was also published, that is, increased risk for premenopausal women. $^{15}$

GSTP1, located on chromosome 11 (11q13), is overexpressed in some tumors and drug resistant cell lines, which may imply its role as a significant factor in acquired resistance to certain anticancer drugs. Board et al ${ }^{16}$ identified two GSTP1 polymorphisms in exon 5 (A313G, Ile105Val, GSTP1*1/*2) and exon 6 (A342G, Ala114Val, GSTP $1{ }^{*} 1{ }^{*} 3$ ). It was shown that the GSTP1 allelic variants generate enzymes with different heat stability and substrate affinity. ${ }^{17}$ Women with the low-activity GSTP $1 * 2 /{ }^{*} 2$ genotype had better survival after breast cancer chemotherapy. ${ }^{18}$

\section{Materials and methods Materials}

Restriction enzymes and deoxynucleotides (dATP, dCTP, dGTP, and dTTP) were products of New England Biolabs (Beverly, MA, USA). UltraPure agarose was supplied by Life Technologies (Paisley, UK). Oligonucleotide primers were synthesized by Generi Biotech (Hradec Králové, CR). Other chemicals were purchased from Sigma Chemical Co. (St Louis, MO, USA). Polymerase chain reaction (PCR) was performed using a GeneAmp 2400 thermocycler (Perkin Elmer, Norwalk, CT, USA) and PTC 200 DNA Engine Thermal Cycler (MJ Research, Waltham, MA, USA).

\section{Subjects}

Blood samples were obtained from 238 incident breast cancer patients (cases). The recruited patients comprised of Caucasian females attended at Departments of Surgery in three Teaching Hospitals in Prague (General Teaching Hospital in Prague 2, Thomayer's Hospital in Prague 4, Teaching Hospital in Motol in Prague 5) in the period November 2001-June 2003. Samples were collected during surgery or biopsy examination. The following data on patients were retrieved from medical records: age, menopausal status, date of diagnosis of breast cancer, personal history, family history (number of relatives affected by breast, ovarian cancer, or other malignant diseases), clinical stage, TNM classification according to UICC, tumor size, histology grade and type of tumor, status of estrogen and progesterone receptors. The main criterion for inclusion of patients into the study was histologically verified breast cancer malignancy. A control group was composed of 313 unrelated women of Caucasian origin. Samples from control subjects were collected during the same period as cases. Controls were recruited from first visit outpatients of three Teaching Hospitals in Prague. Only noncancer controls were included into the study. The composition of control group was comparable to cases in terms of age (cases $59 \pm 14$ years, controls $53 \pm 22$ years), gender (females only), and ethnicity (Caucasians only). Patients and controls were asked to read and sign an informed consent in agreement with requirements of the Ethical Commission of the National Institute of Public Health in Prague.

\section{Genotyping}

Genomic DNA was isolated from peripheral lymphocytes by the phenol/chloroform extraction method described by Sugimura et al. ${ }^{19}$ Genotypes of biotransformation enzymes were assayed with previously published PCR-restriction fragment length polymorphism (RFLP)-based methods. ${ }^{9,20}$ 


\section{Statistical analysis}

In the first round of statistical analyses, we have tested differences in distribution of genotypes between cases and controls by Pearson $\chi^{2}$ test (asymptotic significance two-sided, $\mathrm{df}=2$ ) and calculated crude odds ratios (ORs) from $2 \times 2$ tables by the Mantel-Haenszel statistics (unconditional, $\mathrm{df}=1$ ). Age-adjusted ORs were calculated using binary logistic regression by the Hosmer and Lemeshow test with profile likelihood based 95\% confidence intervals (CI). Then, we analyzed prevalence of selected combinations of genotypes as follows: EPHX1-exon 3+GSTM1, EPHX1-exon 3+GSTT1, EPHX1-exon 3+GSTP1, EPHX1-exon 3+ NQO1; EPHX1activity + GSTM1, EPHX1-activity + GSTT1, EPHX1-activity + GSTP1, EPHX1-activity + NQO1; GSTM1+ GSTT1, GSTM1 + GSTP1, GSTM1 + NQO1; GSTT1 + GSTP1, GSTT1 + NQO1, and GSTP1 + NQO1. The selection of these combinations was based on hypothesis that carrier of at least one variant allele in both combined genes may be at higher risk and thus no correction was applied for multiple testing. For all statistic analyses, Win SPSS v10.0 program (SPSS Inc., Chicago, IL, USA) was used. When group size was less than 40 or when expected values in contingency tables were less than five, Fisher's exact test was used. The $P$-value lower than 0.05 was considered significant.

\section{Results and discussion}

Analysis of the distribution of genetic polymorphisms of biotransformation enzymes in cases and controls The results obtained are summarized in Table 1 . The observed frequencies and genotype distributions in our control group did not differ significantly from data on the majority of other European Caucasian subpopulations. ${ }^{20}$

Most interesting result was obtained by analysis of distribution of genotypes in NQO1-exon 6. Both the difference in distribution of genotypes $\left(\chi^{2}=9.46\right.$, $P=0.009)$ and crude OR analysis were highly significant between cases and controls $(\mathrm{OR}=3.77, \mathrm{CI}=1.46-9.77$, $P=0.004$ for normal $v s$ variant homozygotes, Table 1). Results of logistic regression confirmed that carriers of homozygous genotype $N Q O 1{ }^{*} 2 /{ }^{*} 2$ are at high risk of breast cancer (age-adjusted $\mathrm{OR}=3.68, \mathrm{CI}=1.41-9.61, P=0.008$, Table 2).

Individuals carrying the variant homozygous genotype of NQO1 $\left({ }^{*} 2 /{ }^{*} 2\right)$ lack NQO1 expression. ${ }^{21}$ Quinones and their reduced forms, hydroquinones, are mutagens that adduct DNA. ${ }^{22,23}$ The mutational spectra of quinones, semiquinones (intermediates of transitions between oxidized and reduced forms), and hydroquinones differ from each other with respect to their mutational frequency and specificity. NQO1 protects the cells from quinone muta-

Table 1 Distribution of genotypes in EPHX1, GSTM1, GSTT1, GSTP1, and NQO1 in case-control study

\begin{tabular}{|c|c|c|c|c|c|c|c|}
\hline Gene & Genotype & Controls & Patients & $O R^{\mathrm{a}}$ & $95 \% C l^{\mathrm{a}}$ & $\chi^{2}$ & $P$ \\
\hline $\begin{array}{l}E P H X 1 \\
\text { (exon 3) }\end{array}$ & $\begin{array}{l}* 1 / * 1 \\
* 1 / * 3 \\
* 3 / * 3 \\
N\end{array}$ & $\begin{array}{r}148(47.6) \\
124(39.9) \\
39(12.5) \\
311\end{array}$ & $\begin{array}{r}115(48.5) \\
77(32.5) \\
45(19.0) \\
237\end{array}$ & $\begin{array}{l}-\overline{799} \\
1.485\end{array}$ & $\begin{array}{c}- \\
0.550-1.162 \\
0.907-2.432\end{array}$ & $\begin{array}{l}1 . \overline{379} \\
2.483 \\
5.670^{b}\end{array}$ & $\begin{array}{l}-\overline{240} \\
0.115 \\
0.059^{\mathrm{b}}\end{array}$ \\
\hline $\begin{array}{l}E P H X 1 \\
\text { (exon 4) }\end{array}$ & $\begin{array}{l}* 1 / * 1 \\
* 1 / * 4 \\
* 4 / * 4 \\
N\end{array}$ & $\begin{array}{l}180(58.1) \\
115(37.1) \\
15(4.8) \\
310\end{array}$ & $\begin{array}{r}147(61.8) \\
83(34.9) \\
8(3.4) \\
238\end{array}$ & $\begin{array}{l}\overline{-} \\
0.884 \\
0.653\end{array}$ & $\begin{array}{c}- \\
0.619-1.262 \\
0.269-1.583\end{array}$ & $\begin{array}{l}0 . \overline{461} \\
0.901 \\
1.193^{b}\end{array}$ & $\begin{array}{l}0 . \overline{497} \\
0.343 \\
0.551^{\mathrm{b}}\end{array}$ \\
\hline $\begin{array}{l}\text { GSTM1 } \\
\text { (deletion) }\end{array}$ & $\begin{array}{l}\text { Plus } \\
\text { Null } \\
N\end{array}$ & $\begin{array}{l}156(50.2) \\
155(49.8) \\
311\end{array}$ & $\begin{array}{l}105(44.1) \\
133(55.9) \\
238\end{array}$ & $1 . \overline{275}$ & $0.908-1.789$ & $1 . \overline{974}$ & $0 . \overline{160}$ \\
\hline $\begin{array}{l}\text { GSTT1 } \\
\text { (deletion) }\end{array}$ & $\begin{array}{l}\text { Plus } \\
\text { Null } \\
N\end{array}$ & $\begin{array}{r}266(85.8) \\
44(14.2) \\
310\end{array}$ & $\begin{array}{l}201(85.9) \\
33(14.1) \\
234\end{array}$ & $0 . \overline{993}$ & $0.610-1.615$ & $0 . \overline{001}$ & $0 . \overline{978}$ \\
\hline $\begin{array}{l}\text { GSTP1 } \\
\text { (exon 5) }\end{array}$ & $\begin{array}{l}{ }^{*} 1 /{ }^{*} 1 \\
{ }^{*} 1 /{ }^{*} 2 \\
{ }^{*} 2 /{ }^{*} 2 \\
N\end{array}$ & $\begin{array}{r}146(47.2) \\
132(42.7) \\
31(10.0) \\
309\end{array}$ & $\begin{array}{r}95(40.3) \\
111(47.0) \\
30(12.7) \\
236\end{array}$ & $\begin{array}{l}1 . \overline{281} \\
1.537\end{array}$ & $\begin{array}{c}- \\
0.892-1.839 \\
0.877-2.693\end{array}$ & $\begin{array}{l}1 . \overline{801} \\
2.273 \\
2.898^{b}\end{array}$ & $\begin{array}{l}0 . \overline{180} \\
0.132 \\
0.235^{\mathrm{b}}\end{array}$ \\
\hline $\begin{array}{l}\text { NQO1 } \\
\text { (exon 6) }\end{array}$ & $\begin{array}{l}{ }^{*} 1 /{ }^{*} 1 \\
{ }^{*} 1 /{ }^{*} 2 \\
{ }^{*} 2 /{ }^{*} 2 \\
N\end{array}$ & $\begin{aligned} 221 & (71.3) \\
83 & (26.8) \\
6 & (1.9) \\
310 & \end{aligned}$ & $\begin{array}{r}166(69.7) \\
55(23.1) \\
17(7.1) \\
238\end{array}$ & $\begin{array}{l}0 . \overline{882} \\
3.772\end{array}$ & $\begin{array}{c}- \\
0.594-1.311 \\
1.456-9.775\end{array}$ & $\begin{array}{l}0 . \overline{385} \\
8.453 \\
9.462^{b}\end{array}$ & $\begin{array}{l}\overline{-} \\
0.535 \\
0.004 \\
0.009^{\mathrm{b}}\end{array}$ \\
\hline
\end{tabular}

Numbers of genotype carriers presented (percentages in brackets).

${ }^{a}$ Crude odds ratios and confidence intervals for $2 \times 2$ tables by the Mantel-Haenszel statistics $(d f=1)$.

${ }^{b}$ Distribution of genotypes by the Pearson $\chi^{2}$ test $(\mathrm{df}=2)$. 
Table 2 Age-adjusted OR and 95\% CI for EPHX1, GSTM1, GSTT1, GSTP1, and NQO1 in case-control study

\begin{tabular}{|c|c|c|c|c|}
\hline Gene & Genotype & $O R^{\mathrm{a}}$ & $95 \% \mathrm{Cl}^{\mathrm{a}}$ & $P^{\mathrm{a}}$ \\
\hline $\begin{array}{l}\text { EPHX1 } \\
\text { (exon 3) }\end{array}$ & $\begin{array}{l}{ }^{*} 1 /{ }^{*} 1 \text { vs * } 1 / * 3 \\
{ }^{*} 1 /{ }^{*} 1 \text { vs } * 3 / * 3\end{array}$ & $\begin{array}{l}0.753 \\
1.466\end{array}$ & $\begin{array}{l}0.513-1.107 \\
0.884-2.433\end{array}$ & $\begin{array}{l}0.149 \\
0.138\end{array}$ \\
\hline $\begin{array}{l}\text { EPHX1 } \\
\text { (exon 4) }\end{array}$ & $\begin{array}{l}{ }^{*} 1 /{ }^{*} 1 \text { vs }{ }^{*} 1 /{ }^{*} 4 \\
{ }^{*} 1 /{ }^{*} 1 \text { vs }{ }^{*} 4 /{ }^{*} 4\end{array}$ & $\begin{array}{l}0.917 \\
0.653\end{array}$ & $\begin{array}{l}0.637-1.323 \\
0.261-1.631\end{array}$ & $\begin{array}{l}0.644 \\
0.361\end{array}$ \\
\hline $\begin{array}{l}\text { GSTM1 } \\
\text { (deletion) }\end{array}$ & plus vs null & 1.239 & $0.876-1.751$ & 0.225 \\
\hline $\begin{array}{l}\text { GSTT1 } \\
\text { (deletion) }\end{array}$ & plus vs null & 1.003 & $0.610-1.647$ & 0.991 \\
\hline $\begin{array}{l}\text { GSTP1 } \\
\text { (exon 5) }\end{array}$ & $\begin{array}{l}{ }^{*} 1 /{ }^{*} 1 \text { vs }{ }^{*} 1 /{ }^{*} 2 \\
{ }^{*} 1 /{ }^{*} 1 \text { vs }{ }^{*} 2 /{ }^{*} 2\end{array}$ & $\begin{array}{l}1.287 \\
1.538\end{array}$ & $\begin{array}{l}0.890-1.866 \\
0.861-2.747\end{array}$ & $\begin{array}{l}0.181 \\
0.145\end{array}$ \\
\hline $\begin{array}{l}\text { NQO1 } \\
\text { (exon 6) }\end{array}$ & $\begin{array}{l}{ }^{*} 1 /{ }^{*} 1 \text { vs } * 1 /{ }^{*} 2 \\
{ }^{*} 1 /{ }^{*} 1 \text { vs }{ }^{*} 2 /{ }^{*} 2\end{array}$ & $\begin{array}{l}0.890 \\
3.676\end{array}$ & $\begin{array}{l}0.593-1.335 \\
1.408-9.615\end{array}$ & $\begin{array}{l}0.573 \\
0.008\end{array}$ \\
\hline
\end{tabular}

${ }^{\mathrm{a} A g e-a d j u s t e d ~ o d d s ~ r a t i o s, ~ c o n f i d e n c e ~ i n t e r v a l s, ~ a n d ~ s i g n i f i c a n c e ~ b y ~ b i n a r y ~ l o g i s t i c ~ r e g r e s s i o n ~(H o s m e r ~ a n d ~ L e m e s h o w ~ t e s t) . ~}$

genicity by competing with one-electron donor P450 reductase, which produces highly reactive semiquinones. ${ }^{24}$ Moreover, the frequently used chemotherapy for various tumors by quinone anticancer drugs, anthracyclines (eg doxorubicin, epirubicin), is based on the ability of reduced form to promote apoptosis and bind to DNA-topoisomerase II complex. ${ }^{25}$ Carriers of mutant homozygote genotype have no NQO1 activity and thus basic hypothesis regarding these individuals may be drawn: simultaneous lack of the NQO1 activity and exposure to quinones, for example, products of benzene metabolism promotes mutagenesis and carcinogenesis. Further research is needed to confirm or disprove this hypothesis.

The role of NQO1 as risk factor in breast cancer has not been proposed so far.

According to our results, GSTM1null and GSTT1null (Tables 1 and 2) do not constitute a significant risk factor for breast cancer.

We have noted that the frequency of $G S T P 1{ }^{*} 2 /{ }^{*} 2$ in cases was higher than that in controls $(\mathrm{OR}=1.54, \mathrm{CI}=0.86-$ $2.75, P=0.145$, Table 2). Although this difference was not significant, it complies with previous reports on higher frequency of $G S T P 1{ }^{*} 2 /{ }^{*} 2$ allele in breast cancer cases. ${ }^{26,27}$ GSTP1 is involved in a wide range of detoxifying reactions, for example, conjugation of epoxides, dihydrodiols, products of oxidative stress, etc. and effect of variant alleles may be different at each of these reactions. NedelchevaKristensen et $a l^{28}$ and Gudmundsdottir et $a l^{26}$ found an association of the GSTP $1{ }^{*} 2$ allele with an increased frequency of loss of heterozygozity and mutations in the p53 locus. Thus, it seems that the variant GSTP $1{ }^{*} 2$ or another possibly linked alteration may contribute to the accumulation of genetic damage during tumor progression and further study is needed to clarify the role of this enzyme in breast cancer.
Analysis of EPHX1 genotypes revealed that carriers of $E P H X 1{ }^{*} 3 /{ }^{*} 3$ genotype are over-represented among breast cancer cases $(\mathrm{OR}=1.47, \mathrm{CI}=0.88-2.43, P=0.138$, Table 2$)$. The $E P H X 1^{*} 3$ was assigned as low activity allele by functional study undertaken by Hasset et al. ${ }^{5}$ Therefore, we have constructed EPHX1 activity based on combinations of both genotypes in exons 3 and $4 .^{20}$ Analysis of distribution of the deduced EPHX1 activity between cases and controls confirmed our hypothesis that carriers of low EPHX1 activity may be at higher risk of breast cancer in comparison with carriers of high EPHX1 activity (ageadjusted $\mathrm{OR}=1.60, \mathrm{CI}=0.92-2.78$, Table 3$)$. This result was not statistically significant $(P=0.098)$, but together with the fact that the role of EPHX1 polymorphisms and activity in breast cancer was not studied in detail so far it presents potentially interesting topic for further research.

\section{Analysis of the distribution of combinations of polymorphisms in cases and controls}

Combinations of polymorphisms are not frequently studied due to various reasons including small sample size prone to statistical bias and difficult interpretation. We have constructed several potentially interesting combinations based on the principle of prior hypothesis that presence of variant alleles in two genes may increase risk of breast cancer. Genes coding for generally recognized detoxification enzymes (GSTs and EPHX1) known to interact with environmental factors were selected.

Results revealed that in combination especially EPHX1, GSTP1, and GSTM1 may represent significant modifiers of breast cancer risk (Table 4). Subjects with GSTM1null together with at least one variant GSTP1 allele were at significantly higher risk of breast cancer (age-adjusted $\mathrm{OR}=2.03, \mathrm{CI}=1.18-3.50, P=0.01$, Table 4$)$. In concert 
Table 3 Deduced EPHX1 activity in case-control study

A. Distribution of EPHX1 activity by the Pearson $\chi^{2}$ test $(\mathrm{df}=2)$

\begin{tabular}{lccc} 
EPHX1 activity & Controls & Patients & $\chi^{2}$ \\
\hline low & $109(35.3)$ & $93(39.2)$ & - \\
medium & $138(44.7)$ & $105(44.3)$ & - \\
high & $62(20.1)$ & $39(16.5)$ & $-\overline{-}$ \\
$\mathrm{N}$ & 309 & 237 & 1.518
\end{tabular}

B. Crude odds ratios and confidence intervals for $2 \times 2$ tables by the Mantel-Haenszel statistics $(\mathrm{df}=1)$

\begin{tabular}{lcccc} 
EPHX1 activity & OR & $95 \% \mathrm{Cl}$ & $\chi^{2}$ \\
\hline medium vs low & 1.412 & $0.922-1.412$ & $2.528(1)$ & 0.112 \\
medium vs high & 0.858 & $0.544-1.354$ & $0.432(1)$ & 0.511 \\
high vs low & 1.647 & $0.956-2.833$ & $3.253(1)$ & 0.071
\end{tabular}

C. Age-adjusted odds ratios, confidence intervals, and significance by binary logistic regression (Hosmer and Lemeshow test)

\begin{tabular}{lccc} 
EPHX1 activity & OR & $95 \% \mathrm{Cl}$ & $P$ \\
\hline medium vs low & 1.429 & $0.922-2.214$ & 0.110 \\
medium vs high & 0.895 & $0.563-1.425$ & 0.640 \\
high vs low & 1.597 & $0.918-2.778$ & 0.098 \\
\hline
\end{tabular}

Numbers of genotype carriers presented (percentages in brackets).

EPHX1 activity was deduced according to previously published method ${ }^{20}$ from combinations of the following genotypes: EPHX1 (exon 3+exon 4), low: $3 /{ }^{*} 3+{ }^{*} 1 /{ }^{*} 1,{ }^{*} 3 /{ }^{*} 3+{ }^{*} 1 /{ }^{*} 4,{ }^{*} 1 /{ }^{*} 3+{ }^{*} 1 /{ }^{*} 1$, and ${ }^{*} 3 /{ }^{*} 3+{ }^{*} 4 /{ }^{*} 4$; medium: ${ }^{*} 1 /{ }^{*} 1+{ }^{*} 1 /{ }^{*} 1,{ }^{*} 1 /{ }^{*} 3+{ }^{*} 1 /{ }^{*} 4$, and ${ }^{*} 1 /{ }^{*} 3+{ }^{*} 4 /{ }^{*} 4 ;$ high: ${ }^{*} 1 /{ }^{*} 1+{ }^{*} 1 /{ }^{*} 4,{ }^{*} 1 /{ }^{*} 1$ $+{ }^{*} 4 /{ }^{*} 4$.

Table 4 Combinations of genotypes in case-control study

\begin{tabular}{|c|c|c|c|c|c|}
\hline Combination & Controls & Patients & $O R^{\mathrm{a}}$ & $95 \% \mathrm{Cl}^{\mathrm{a}}$ & $P^{\mathrm{a}}$ \\
\hline \multirow{3}{*}{$\begin{array}{l}\text { GSTM1 plus+GSTP } 1 * 1 /{ }^{*} 1 \\
\text { vs GSTM1 null+GSTP } 1 * 1 /{ }^{*} 2 \\
\text { and GSTM1 null+GSTP } 1{ }^{*} 2 /{ }^{*} 2 \\
N\end{array}$} & 79 & 30 & \multirow{3}{*}{$2 . \overline{033}$} & \multirow{3}{*}{$1.182-3.497$} & \multirow{3}{*}{$0 . \overline{010}$} \\
\hline & 87 & 68 & & & \\
\hline & 166 & 98 & & & \\
\hline \multirow{3}{*}{$\begin{array}{l}\text { GSTM1 plus+EPHX1 }{ }^{*} 1 /{ }^{*} 1 \\
\text { vs GSTM1 null+EPHX } 1 * 3 / * 3 \\
N\end{array}$} & 74 & 50 & \multirow{3}{*}{$\overline{2 .} \overline{151}$} & \multirow{3}{*}{$1.020-4.525$} & \multirow{3}{*}{$0 . \overline{04}$} \\
\hline & 19 & 25 & & & \\
\hline & 93 & 75 & & & \\
\hline \multirow{3}{*}{$\begin{array}{l}\text { GSTM1 plus+EPHX1-medium } \\
\text { vs GSTM1 null+EPHX1-low } \\
N\end{array}$} & 101 & 61 & \multirow{3}{*}{$\overline{1.880}$} & \multirow{3}{*}{$1.003-3.521$} & \multirow{3}{*}{$0 . \overline{04}$} \\
\hline & 31 & 32 & & & \\
\hline & 132 & 93 & & & \\
\hline \multirow{3}{*}{$\begin{array}{l}\text { GSTP } 1{ }^{*} 1 /{ }^{*} 1+\text { EPHX } 1 \text {-high } \\
\text { vs GSTP } 1 * 1 /{ }^{*} 2+\text { EPHX } 1 \text {-low } \\
\text { and GSTP } 1{ }^{*} 2{ }^{*} 2+\text { EPHX } 1 \text {-low } \\
N\end{array}$} & 38 & 19 & \multirow{3}{*}{$2 . \overline{398}$} & \multirow{3}{*}{$1.152-5.000$} & \multirow{3}{*}{$0 . \overline{019}$} \\
\hline & 30 & 37 & & & \\
\hline & 68 & 56 & & & \\
\hline \multirow{3}{*}{$\begin{array}{l}\text { NQO1 }{ }^{*} 1 /{ }^{*} 1+\text { EPHX1-high } \\
\text { vs NQO }{ }^{*} 2 /{ }^{*} 2+\text { EPHX-low } \\
N\end{array}$} & 47 & 26 & \multirow{3}{*}{$9 . \overline{804}$} & \multirow{3}{*}{$1.110-83.333$} & \multirow{3}{*}{$0 . \overline{04 C}$} \\
\hline & 1 & 6 & & & \\
\hline & 48 & 32 & & & \\
\hline
\end{tabular}

Only significant results presented. Numbers of genotype carriers presented.

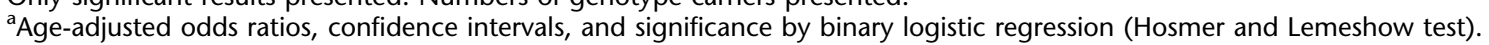

with the concept of decreased conjugation capacity, combination of GSTM1null and GSTP1*2 alleles was significantly associated with an elevated risk of lung carcinoma $(\mathrm{OR}=6.9, \mathrm{CI}=1.6-30.2)^{29}$ and $(\mathrm{OR}=2.4$, $\mathrm{CI}=1.1-5.1),{ }^{30}$ bladder cancer $(\mathrm{OR}=3.9, \mathrm{CI}=1.9-8.1),{ }^{31}$ and prostate cancer $(\mathrm{OR}=2.7, \mathrm{CI}=1.1-6.6){ }^{32}$
GSTM1 modified the risk of breast cancer also in combination with EPHX1. The combination of variant genotypes of GSTM1null and EPHX1*3/*3 was found as risk factor (age-adjusted $\mathrm{OR}=2.15, \mathrm{CI}=1.02-4.53, P=0.044$; Table 4). This result was confirmed by analysis of deduced EPHX1 activity (age-adjusted $\mathrm{OR}=1.88, \mathrm{CI}=1.00-3.52$, 
$P=0.049)$. Thus, individuals lacking GSTM1 and simultaneously having low EPHX1 activity are at significantly higher risk of breast cancer than those with normal genotypes. Similarly, GSTP1 variants contributed to the risk of low EPHX1 activity (age-adjusted $\mathrm{OR}=2.40$, $\mathrm{CI}=1.15-5.00, P=0.019$, Table 4). EPHX1 metabolizes wide spectra of xenobiotics, for example, ethylene oxide and reactive metabolites of benzene, styrene, and butadiene present in cigarette smoke, engine exhausts, industrial and household sources. It was found that individuals exposed to styrene carrying alleles predisposing to low and medium EPHX1 activity exhibited higher frequencies of chromosomal aberrations than individuals with highactivity alleles. ${ }^{33}$ Similar tendency was observed in individuals exposed to butadiene (unpublished data). Thus, we may speculate that highly lipophillic organic solvents as styrene (partition coefficient for fat:blood is 93.8, for lung:blood is 1.46$)^{34}$ may accumulate in breast fat and prolong exposure of this tissue to metabolism-related mutagens. Expression of EPHX1 in breast tissue was already reported $^{35}$ and there is also a considerable amount of data on styrene genotoxicity. ${ }^{33}$ The role of oxidative stress should be noted as well. Breast tissues of patients with the suggested high-activity genotype of GSTP1 (*1/*1) contained lower level of 8-hydroxy-2'-deoxyguanosine, marker of oxidative DNA damage when compared with patients carrying the low-activity alleles. ${ }^{36}$ Both EPHX1 low activity and GSTP1 variant alleles were associated with higher genotoxicity of styrene-7,8-oxide in vitro (by micronucleus test) in the recently published study of Laffon et al. ${ }^{37}$

Carriers of both NQO1*2/*2 genotype and low EPHX1 activity prevailed among cases, but due to low numbers in the analyzed groups (Table 4) this result should be taken with caution.

Taken together, our findings seem to suggest an influence of genetic polymorphisms of xenobiotic-metabolizing enzymes, particularly NQO1, on the susceptibility to breast cancer, possibly by change of the ratio of activation/ detoxification of procarcinogens or by linkage to another cancer-causative gene(s). The above-discussed results suggest that EPHX1 may be attractive gene for further study of breast cancer risk. Owing to low numbers of cases in studied groups and the fact that no correction was applied for multiple testing, the study of combinations of genotypes should be considered as exploratory and providing inspiration for focusing further research on risk factors and understanding the molecular mechanisms underlying the development and progression of breast cancer.

\section{Acknowledgements}

We express our sincere thanks to doctors and nurses of Teaching Hospitals in Praha and to all patients and recruited control subjects for their essential help and understanding. Jana Sarmanova was partly supported by stipend of the third Medical Faculty of the Charles
University in Prague, Czech Republic. The work at this project was supported by grant of Grant Agency of the Czech Republic, Grant No.: 310/01/1537.

\section{References}

1 Greenlee RT, Murray T, Bolden S, Wingo PA: Cancer statistics, 2000. CA Cancer J Clin 2000; 50: 7-33.

2 Vineis P, Malats N, Lang M et al (eds): Metabolic polymorphisms and susceptibility to cancer, IARC Sci Publ No. 148, Lyon, France: IARC, 1999.

3 Raunio H, Husgafvel-Pursiainen K, Anttila S, Hietanen E, Hirvonen A, Pelkonen O: Diagnosis of polymorphism in carcinogen-activating and inactivating enzymes and cancer susceptibility - a review. Gene 1995; 159: 113-121.

4 Oesch F: Mammalian epoxide hydrases: inducible enzymes catalysing the inactivation of carcinogenic and cytotoxic metabolites derived from aromatic and olefinic compounds. Xenobiotica 1973; 3: 305-340.

5 Hassett C, Aicher L, Sidhu JS, Omiecinski CJ: Human microsomal epoxide hydrolase: genetic polymorphism and functional expression in vitro of amino acid variants. Hum Mol Genet 1994; 3: $421-428$.

6 Spurdle AB, Purdie DM, Webb PM, Chen X, Green A, ChenevixTrench G: The microsomal epoxide hydrolase Tyr113His polymorphism: association with risk of ovarian cancer. Mol Carcinog 2001; 30: 71-78.

7 Traver RD, Siegel D, Beall HD et al: Characterization of a polymorphism in $\mathrm{NAD}(\mathrm{P}) \mathrm{H}$ :quinone oxidoreductase (DTdiaphorase). Br J Cancer 1997; 75: 69-75.

8 Harth V, Donat S, Ko Y, Abel J, Vetter H, Bruning T: NAD(P)H quinone oxidoreductase 1 codon 609 polymorphism and its association to colorectal cancer. Arch Toxicol 2000; 73: 528-531.

9 Larson RA, Wang $\mathrm{Y}$, Banerjee $\mathrm{M}$ et al: Prevalence of the inactivating ${ }^{609} \mathrm{C} \rightarrow \mathrm{T}$ polymorphism in the $\mathrm{NAD}(\mathrm{P}) \mathrm{H}$ : quinone oxidoreductase (NQO1) gene in patients with primary and therapy-related myeloid leukemia. Blood 1999; 94: 803-807.

10 Hamajima $\mathrm{N}$, Matsuo $\mathrm{K}$, Iwata $\mathrm{H}$ et al: $\mathrm{NAD}(\mathrm{P}) \mathrm{H}$ : quinone oxidoreductase 1 (NQO1) C609T polymorphism and the risk of eight cancers for Japanese. Int J Clin Oncol 2002; 7: 103-108.

11 Siegelmann-Danieli N, Buetow KH: Significance of genetic variation at the glutathione $S$-transferase $\mathrm{M} 1$ and $\mathrm{NAD}(\mathrm{P}) \mathrm{H}$ :quinone oxidoreductase 1 detoxification genes in breast cancer development. Oncology 2002; 62: 39-45.

12 d'Errico A, Taioli E, Chen X, Vineis P: Genetic metabolic polymorphisms and the risk of cancer, a review of the literature. Biomarkers 1996; 1: 149.

13 Pemble S, Schroeder KR, Spencer SR et al: Human glutathione $S$-transferase theta (GSTT1): cDNA cloning and the characterization of a genetic polymorphism. Biochem J 1994; 300: $271-276$.

14 Mitrunen K, Jourenkova $\mathrm{N}$, Kataja $\mathrm{V}$ et al: Glutathione $S$-transferase M1, M3, P1, and T1 genetic polymorphisms and susceptibility to breast cancer. Cancer Epidemiol Biomark Prev 2001; 10: 229-236.

15 Park SK, Yoo KY, Lee SJ et al: Alcohol consumption, glutathione $S$-transferase $\mathrm{M} 1$ and $\mathrm{T} 1$ genetic polymorphisms and breast cancer risk. Pharmacogenetics 2000; 10: 301-309.

16 Board PG: Isolation of a cDNA clone and localization of the human glutathione $S$-transferase 3 genes to chromosome band $11 q 13$ and 12q13-14. Ann Hum Genet 1989; 53: 205-213.

17 Zimniak P, Nanduri B, Pikula S et al: Naturally occuring human glutathione $S$-transferase GSTP1-1 isoforms with isoleucine and valine in position 104 differ in enzymic properties. Eur J Biochem 1994; 224: 893-899.

18 Sweeney C, McClure GY, Fares MY et al: Association between survival after treatment for breast cancer and glutathione $S$-transferase P1 Ile105Val polymorphism. Cancer Res 2000; 60: $5621-5624$ 
19 Sugimura H, Caporaso NE, Shaw GL et al: Human debrisoquine hydroxylase gene polymorphisms in cancer patients and controls. Carcinogenesis 1990; 11: 1527-1530.

20 Šarmanová J, Tỳnková L, Šůsová S, Gut I, Souček P: Genetic polymorphisms of biotransformation enzymes: allele frequencies in the population of the Czech Republic. Pharmacogenetics 2000; 10: $781-788$.

21 Siegel D, McGuinness SM, Winski SL, Ross D: Genotype-phenotype relationships in studies of a polymorphism in NAD $(\mathrm{P}) \mathrm{H}$ : quinone oxidoreductase 1. Pharmacogenetics 1999; 9: 113-121.

22 Lin PH, Nakamura J, Yamaguchi S, Upton PB, La DK, Swenberg JA: Oxidative damage and direct adducts in calf thymus DNA induced by the pentachlorophenol metabolites, tetrachlorohydroquinone and tetrachloro-1,4-benzoquinone. Carcinogenesis 2001; 22: 627-634.

23 Arif JM, Lehmler HJ, Robertson LW, Gupta RC: Interaction of benzoquinone- and hydroquinone-derivatives of lower chlorinated biphenyls with DNA and nucleotides in vitro. Chem Biol Interact 2003; 142: 307-316.

24 Joseph P, Jaiswal AK: NAD(P)H:quinone oxidoreductase 1 reduces the mutagenicity of DNA caused by NADPH:P450 reductaseactivated metabolites of benzo(a)pyrene quinones. $\mathrm{Br} J$ Cancer 1998; 77: 709-719.

25 Binaschi M, Bigioni M, Cipollone A et al: Anthracyclines: selected new developments. Curr Med Chem Anti-Canc Agents 2001; 1: $113-130$

26 Gudmundsdottir K, Tryggvadottir L, Eyfjord JE: GSTM1, GSTT1, and GSTP1 genotypes in relation to breast cancer risk and frequency of mutations in the p53 gene. Cancer Epidemiol Biomark Prev 2001; 10: 1169-1173.

27 Helzlsouer KJ, Selmin O, Huang HY et al: Association between glutathione $S$-transferase M1, P1, and T1 genetic polymorphisms and development of breast cancer. J Natl Cancer Inst 1998; 90: $512-518$.

28 Nedelcheva-Kristensen V, Andersen TI, Erikstein B et al: Single tube multiplex polymerase chain reaction genotype analysis of
GSTM1, GSTT1 and GSTP1: relation of genotypes to TP53 tumor status and clinicopathological variables in breast cancer patients. Pharmacogenetics 1998; 8: 441-447.

29 Stucker I, Hirvonen A, de Waziers I et al: Genetic polymorphisms of glutathione $S$-transferases as modulators of lung cancer susceptibility. Carcinogenesis 2002; 23: 1475-1481.

30 Wang J, Deng Y, Cheng J, Ding J, Tokudome S: GST genetic polymorphisms and lung adenocarcinoma susceptibility in a Chinese population. Cancer Lett 2003; 201: 185-193.

31 Toruner GA, Akyerli C, Ucar A et al: Polymorphisms of glutathione S-transferase genes (GSTM1, GSTP1 and GSTT1) and bladder cancer susceptibility in the Turkish population. Arch Toxicol 2001; 75: 459-464.

32 Nakazato $\mathrm{H}$, Suzuki $\mathrm{K}$, Matsui $\mathrm{H}$ et al: Association of genetic polymorphisms of glutathione-S-transferase genes (GSTM1, GSTT1 and GSTP1) with familial prostate cancer risk in a Japanese population. Anticancer Res 2003; 23: $2897-2902$.

33 Vodicka P, Soucek P, Tates AD et al: Association between genetic polymorphism and biomarkers in styrene-exposed workers. Mutat Res 2001; 482: 89-103.

34 Arms AD, Travis CC: Reference physiological parameters in pharmacokinetic modeling; US Environmental Protection Agency, EPA/600/6-88/004,: 1988.

35 Coller JK, Fritz P, Zanger UM et al: Distribution of microsomal epoxide hydrolase in humans: an immunohistochemical study in normal tissues, and benign and malignant tumours. Histochem $J$ 2001; 33: 329-336.

36 Matsui A, Ikeda $\mathrm{T}$, Enomoto $\mathrm{K}$ et al: Increased formation of oxidative DNA damage, 8-hydroxy-2'-deoxyguanosine, in human breast cancer tissue and its relationship to GSTP1 and COMT genotypes. Cancer Lett 2000; 151: 87-95.

37 Laffon B, Perez-Cadahia B, Pasaro E, Mendez J: Effect of epoxide hydrolase and glutathione $S$-tranferase genotypes on the induction of micronuclei and DNA damage by styrene-7, 8-oxide in vitro. Mutat Res 2003; 536: 49-59. 